\title{
Effects of Alternating Magnetic Field on the Metabolism of the Healthy and Diabetic Organisms
}

\author{
Issıl Öcal ${ }^{* 1}$, Tunaya Kalkan ${ }^{2}$ and İsmail Günay ${ }^{1}$ \\ ${ }^{l}$ Cukurova University; Medical Faculty; Department of Biophysics; iocal@cu.edu.tr; Balcali/Adana - Turkey. \\ ${ }^{2}$ Istanbul University; Cerrahpasa Medical Faculty; Department of Biophysics, Istanbul - Turkey
}

\begin{abstract}
The aim of this study was to determine the effects of alternating magnetic field on the metabolism of the healthy and diabetic rats. The rats were divided into two experimental groups. Magnetic fields of 5 and $8 m T$ intensity was applied to the first group of rats for 3 weeks $\left(C_{5 m T}, C M F_{5 m T}, C_{8 m T}\right.$ and $\left.C M F_{8 m T}\right)$. The second group was identified as diabetics group and $5 m T$ was applied $\left(D_{5 m T}\right.$ and $\left.D M F_{5 m T}\right)$. The control groups $\left(C_{5 m T}, C_{8 m T}, D_{5 m T}\right)$ of applied magnetic fields were placed in the same cage of the rats in experimental groups that have the same conditions but no pass current. The weights of rats exposed to magnetic fields in experimental groups were increased to initial weight; the plasma glucose levels were decreased in the blood parameters of the healthy and diabetic rats that they were exposed to $5 \mathrm{mT}$ and $8 \mathrm{mT}$ intensity magnetic fields. The decrease of the level of the total cholesterol and triglyceride in the blood plasma of the rats, showed that magnetic fields affected the hormonal systems, directly or indirectly, and slowed down the metabolism or hidratation.
\end{abstract}

Key words: Alternating magnetic field, diabetic rats, blood plasma parameters, physiological conditions

\section{INTRODUCTION}

Electrical forces keep numerous structures of living-organism. The ionized electromagnetic fields affect on these structures is known. For instance, cancer incidence is increased among people living around high voltage power lines (Jauchem et al., 1991). However, the biological effects of low-frequency non-ionized electromagnetic fields have been noticed (Bellossi 1992, Franceschetti et al., 1989). According to Daşdağ et al.(1993), it is reported the people who use mobile phone and work in TV and radio transmitters have insomnia and restlessness. It is natural for the children to be effected more than the adults. The effects of non-ionizing electromagnetic fields on the human body may be both of a pathological type and useful for the therapeutic purposes. As regards the damaging effects most commonly studied (Suess et al., 1989), the studies which appeared to demonstrate a positive or negative affected in the blood and serum or plasma chemistry of diabetic and healthy rats were studied. The biological basis of the effects of the magnetic fields on the cells in highly complex. In an ideal cell at rest, the proteins are distributed evenly over the membrane, but in the presence of an electric field crossing the membrane, they undergo electrophoretic attraction or repulsion, tending to shift towards the poles which the cell presents in the directions of the electric field. Therefore, the cell membrane, by virtue of its bioelectrical properties, is the site where influences of this type are mostly likely to be exerted, though other possible candidates are the large macromolecules organized in repetitive

*Author for correspondence 
units, such as the nucleic acids (Popp et al., $1985,1989)$, or the proteins of the cytoskeleton, particularly the microtubules (Hameroff, 1990).

Diabetes has profound effects on the metabolism of variety of tissues of diabetic animals, both glycolysis and glucose oxidations are decreased and there is an overall decrease in ATP production. (Behari et al., 1997). There were investigations revealing an increase in insulin release in diabetic rats, increase in glycogen, and decrease in glucose level in rats exposed to magnetic fields (Gordon et al., 1981, Shepherd et al., 1978), have demonstrated that the blood cholesterol, glucose and triglyceride levels of diabetic rats were lowered by acute exposure to magnetic field. The sinusoidal magnetic field can be affected on direct or hormonal system that on retard of liver metabolism or the other metabolism. Some researcher that studied concerned with magnetic field referred similar exchanges too (Bellossi et al., 1998, Shepherd et al., 1978). Gordon (1981) showed the selective effect of alternating electromagnetic fields on atherosclerotic lesions without harming the blood vessels, by demonstrating the biophysical changes caused by the electromagnetic fields on the atherosclerotic plaques which led to suggestion that this could serve as a new field in the selective treatment of atherosclerosis.

In this study, the aim was to examine the effects of alternative magnetic field with different period and intensity on the environmental conditions, body weights and blood plasma parameters of the diabetic and healthy rats.

\section{MATERIALS AND METHODS}

\section{Experimental Groups}

Eighty albino Wistar spp rats weighing between 210-260 g were used. Magnetic fields of 5 and $8 \mathrm{mT}$ intensity was applied to the groups of rats for three weeks $\left(\mathrm{C}_{5 \mathrm{mT}}, \mathrm{CMF}_{5 \mathrm{mT}}, \mathrm{C}_{8 \mathrm{mT}}\right.$ and $\mathrm{CMF}_{8 \mathrm{mT}}$. The rats were kept in seven separate, stainless steel cages. The distance between the control and diabetic group cages was three meters. All the animals were fed and watered ad libitum and kept in an environmentally controlled room at $21-23{ }^{\circ} \mathrm{C}$ at relative humidity of $40-50 \%$ with a light/dark cycle of $12 / 12 \mathrm{~h}$. Air of the room was continuously refreshed at a rate $35 \mathrm{~m}^{3}$ with ventilator.

\section{Diabetic Group}

Stretozotocine (STZ, $45 \mathrm{mg} / \mathrm{kg}$ ) dissolved in a citrate buffer solution $(\mathrm{pH} 4.5)$ was injected in to the tail vein of 4-week-old male Wistar rats to induce diabetes $\left(\mathrm{D}_{5 \mathrm{mT}}\right)$ as previously described (Chatham et al., 1993). Control rats $\left(\mathrm{C}_{5 \mathrm{mT}}\right)$ of the same age were injected with a similar volume of buffer solution without STZ. A drop of urine was obtained at $48 \mathrm{~h}$ after the administration of STZ to verify hyperglycemia using semi-quantitatively a glucose strip (glucose, Roche). During the experimental period, the rats were given limitless pellet food and tap water. The amount of the food and tap water consumed by rats are measured everyday and relative humidity, air pressure and temperature of room, temperature of cages, rectal temperature and body weights of the rats were measured twice a day, once in the morning and once in the evening.

\section{Application of Alternating Magnetic Field}

The modulated magnetic field (MMF) was generated with the modulated AC power supply in a specially designed in a solenoid, as previously described (İteğin et al., 1995). Eight rats were placed in a plexiglas cage in order to expose them to the modulated magnetic field. The rats were exposed to $5 \mathrm{mT}$ and $8 \mathrm{mT}$ intensity modulated magnetic field for $165 \mathrm{~min} /$ day (Ocal et al, 2004). MMF exposed to the $\mathrm{CMF}_{5 \mathrm{mT}}$ and $\mathrm{DMF}_{5 \mathrm{mT}}$ group between 8:30 $\mathrm{AM}$ and 11:30 $\mathrm{AM}$ and between 12:00 PM and 15:00 PM, respectively. Exposure was applied for three weeks. The solenoid was always orientated in a north-south direction and its temperature was maintained at between $21-23{ }^{\circ} \mathrm{C}$ with good ventilation. The magnetic field exposure was applied in a separate room apart from that for the $\mathrm{C}$ and $\mathrm{D}$ groups, and the animals were not exposed to the electrical transients when the field was turned on and off (Ocal et al.,2004). They were kept in a room at $21-23{ }^{\circ} \mathrm{C}$ with a $12 \mathrm{~h}$ light/dark cycle. Stray fields were measured at the housed location of animals and the average value was estimated as $0.4 \pm 0.1 \mathrm{G}$. The rats were allowed free access to the standard laboratory food and water, ad libitum. The rats in each group weighed once a week for the one-month period.

The cage made of the plexiglas was placed in system of magnetic field. The rats in the $\mathrm{CMF}_{5 \mathrm{mT}}$, $\mathrm{CMF}_{8 \mathrm{mT}}$ and $\mathrm{DMF}_{5 \mathrm{mT}}$ groups were formed by exposing to a $5 \mathrm{mT}$ and $8 \mathrm{mT}$ intensity, $50 \mathrm{~Hz}$ frequency, north-south oriented magnetic field. They were kept in a room at $21-23{ }^{\circ} \mathrm{C}$ with a $12 \mathrm{~h}$ 
light/dark cycle. The rats were allowed free access to standard laboratory food and tap water, ad libitum. The control and diabetic control groups of applied magnetic fields were placed in the same cage of the rats in experimental groups that have the same conditions but no pass current. Everyday, all of the rats were trained to be held by the hand for 5-10 minutes a-day against the stress of the experimental conditions. At the end of the month, blood of rats was collected to measure the blood plasma parameters.

\section{Statistical analysis}

The unpaired Student-t test and Mann-Whitney U test was used to determined statistical significance between two groups (C and CMF or D and DMF). Significance was set at $\mathrm{p}<0.05$.

\section{RESULTS}

During the experimental period, the measured physical conditions of the room and cages, food and water consumed by the rats are demonstrated mean \pm SEM in Tables 1- and 2. Comparison of the weights of the rats showed increases in the $\mathrm{C}_{5 \mathrm{mT}}$ and $\mathrm{CMF}_{5 \mathrm{mT}}, \mathrm{C}_{8 \mathrm{mT}}$ and $\mathrm{CMF}_{8 \mathrm{mT}}$ groups and slow down of loss weight in $\mathrm{D}_{5}$ and $\mathrm{DMF}_{5}$ groups after the 21 days experimental period (Figs 1,2). In the blood plasma chemistry (total-cholesterol and triglyceride), the rats in $\mathrm{CMF}_{5 \mathrm{mT}}$ and $\mathrm{DMF}_{5 \mathrm{mT}}$ groups showed decreases according to rats in $\mathrm{C}_{5 \mathrm{mT}}$ and $\mathrm{D}_{5 \mathrm{mT}}$ groups The plasma total cholesterol and triglyceride levels in $\mathrm{CMF}_{5 \mathrm{mT}}$ and $\mathrm{DMF}_{5 \mathrm{mT}}$ groups were significantly reduced $(\mathrm{p}<0.05)$ (Fig 4.). The plasma glucose levels were significantly decreased in $\mathrm{CMF}_{5 \mathrm{mT}}$ and $\mathrm{DMF}_{5 \mathrm{mT}}$ by comparison with the controls (Fig 3.). But the other hematological data were not different $(p>0.05)$ from that of the controls. Therefore, they were not shown.

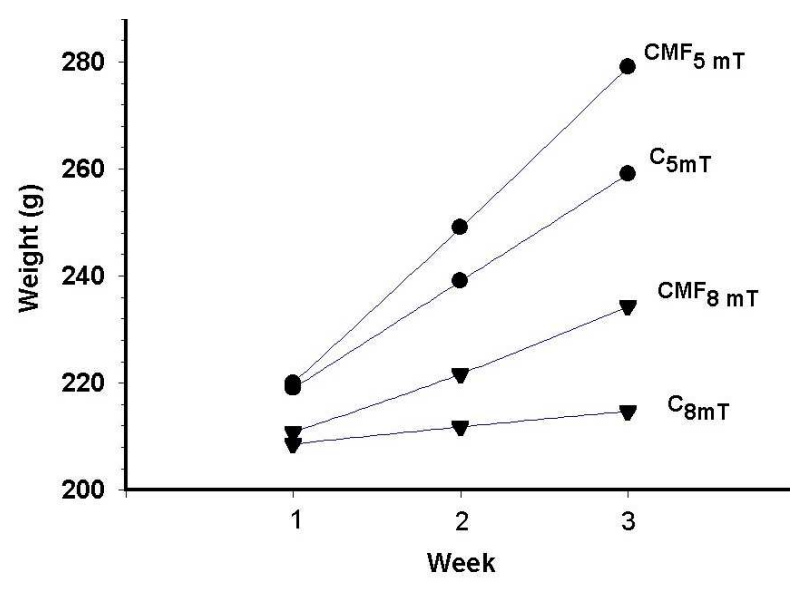

Figure 1- The body weights of rats exposed to $5 \mathrm{mT}$ and $8 \mathrm{mT}$ intensity magnetic field in experimental $\left(\mathrm{CMF}_{5 \mathrm{mT}}, \mathrm{CMF}_{8 \mathrm{mT}}\right.$ and control groups $\left(\mathrm{C}_{5 \mathrm{mT}}, \mathrm{C}_{8 \mathrm{mT}}\right)$ during experimental period (mean \pm SEM)

\section{DISCUSSION}

A special attention must be devoted to the Earth's magnetic field, which provides an important source of directional information for the terrestrial organisms, but the sensory receptors responsible for the magnetic field detection have yet to be identified in most cases. Because of the ubiquitous nature of the geomagnetic field, its low intensity, its capability of acting inside the cell, there in surge of interest in the related effects. The only acceptable guess is that magnetoreception mechanisms could be based on the electromotive force related to $\mathbf{v} \times \mathbf{B}$. The successful utilisation of the Fe storage protein ferritin as an environment in which to achieve the controlled precipitation of nanometric magnetite particles (Meldrum et al., 1992). could be relevant to the elucidation of iron 
oxide biomineralization processes (Mann et al., 1992). Since the induced current effects are believed to be regulated initially by the ionic control mechanisms, the incorporation of these approaches could be useful for the development of the mechanistic models of the action of these currents on the cells. The evaluation of the electric and magnetic fields near a cell membrane, due to an external source (either electrodes, or capacitive coupling or magnetic induction or antenna radiators or mechanical transduction), is possible. The next step is to consider their effects on the cell processes. The real time response of the living cell membranes to small electromagnetic signals has been quantified using the impedance techniques in the frequency domain, linking the theory to the experimental characterisation. This was carried out by first using an electrochemical kinetic approach. It is necessary to recall that the plasma membrane (and other organelle surfaces) exhibit electrical charge separation giving it capacitor-like properties (about $1 \mu \mathrm{F} / \mathrm{cm} 2$ ). In addition, this capacitor is "leaky" since transmembrane ion transport occurs, while other ions can be adsorbed at specific membrane sites. Currents can cross the cell membrane via a complex set of electrochemical steps (Pilla et al., 1977).

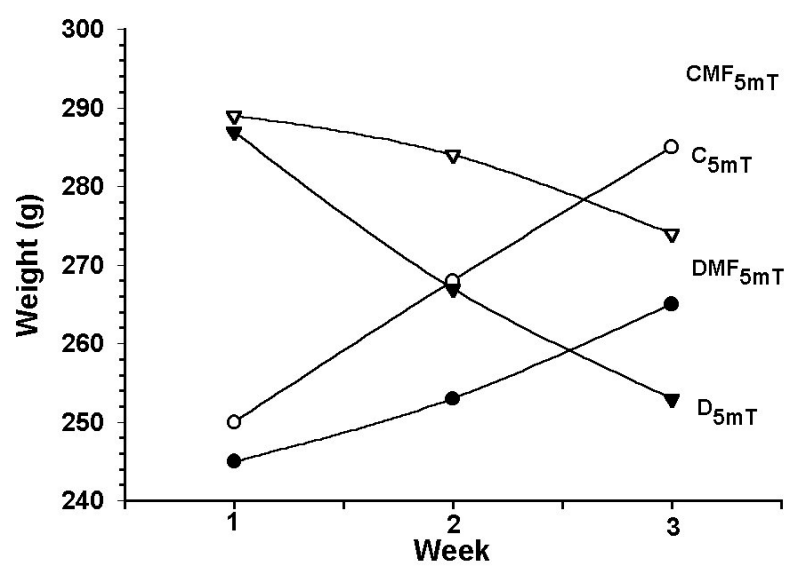

Figure 2 - The body weights of rats exposed to $5 \mathrm{mT}$ intensity magnetic field in diabetic $\left(\mathrm{D}_{5 \mathrm{mT}}\right.$, $\left.\mathrm{DMF}_{5 \mathrm{mT}}\right)$ and control groups $\left(\mathrm{C}_{5 \mathrm{mT}}, \mathrm{CMF}_{5 \mathrm{mT}}\right)$ during experimental period (mean \pm SEM) 


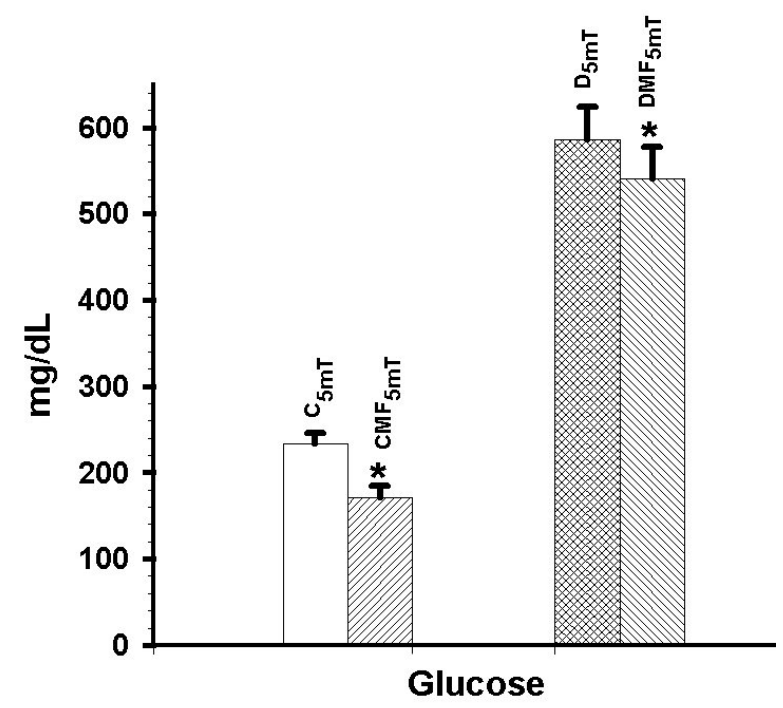

Figure 3 - The levels of plasma glucose of rats in each group $\left(\mathrm{C}_{5 \mathrm{mT}}, \mathrm{CMF}_{5 \mathrm{mT}}, \mathrm{D}_{5 \mathrm{mT}}\right.$ and $\left.\mathrm{DMF}_{5 \mathrm{mT}}\right)$ that exposed to $5 \mathrm{mT}$ intensity magnetic field. (mean $\pm \mathrm{SEM}$ )

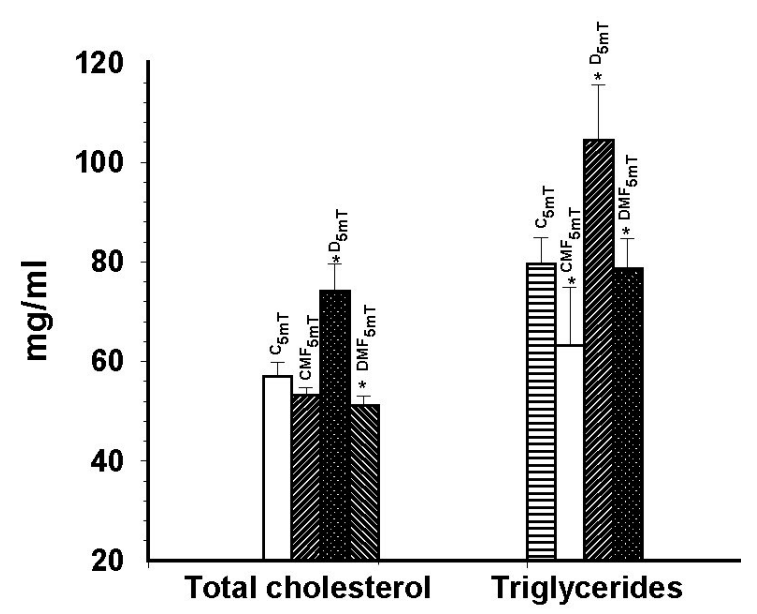

Figure 4 - The levels of plasma total cholesterol and triglyceride of rats in control and diabetic groups $\left(\mathrm{C}_{5 \mathrm{mT}}, \mathrm{CMF}_{5 \mathrm{mT}}, \mathrm{D}_{5 \mathrm{mT}}\right.$ and $\left.\mathrm{DMF}_{5 \mathrm{mT}}\right)$ that exposed to $5 \mathrm{mT}$ intensity magnetic field (mean $\pm \mathrm{SEM}$ )

Table 1- Physical conditions as temperature, air pressure and relative humidity of room and cage in rats exposed to $8 \mathrm{mT}$ intensity magnetic field $\left(\mathrm{CMF}_{8 \mathrm{mT}}\right)$ or not $\left(\mathrm{C}_{8 \mathrm{mT}}\right)$ were measured during three weeks. The values are demonstrated mean \pm SEM

\begin{tabular}{lccc}
\hline & Inside of room & $\begin{array}{c}\text { Inside of Cage } \\
\mathbf{C}_{\mathbf{8 m T}}\end{array}$ & $\begin{array}{c}\text { Inside of Cage } \\
\mathbf{C M F}_{\mathbf{8 m}}\end{array}$ \\
\hline $\begin{array}{l}\text { Temperature } \\
\left(\begin{array}{l}\mathbf{C}) \\
\text { Air Pressure } \\
(\mathbf{m m H g})\end{array}\right.\end{array}$ & $21.7 \pm 1.6$ & $23.2 \pm 1.9$ & $23.4 \pm 1.7$ \\
$\begin{array}{l}\text { Relative Humidity } \\
\text { Ratio (\%) }\end{array}$ & $756.6 \pm 14.3$ & --- & --- \\
\hline
\end{tabular}


Table 2- Rectal temperatures of rats and the amount of the food and water consumed by rats exposed to $8 \mathrm{mT}$ intensity magnetic field $\left(\mathrm{CMF}_{8 \mathrm{mT}}\right)$ or not $\left(\mathrm{C}_{8 \mathrm{mT}}\right)$ were measured during three weeks. The values are demonstrated mean \pm SEM

\begin{tabular}{|c|c|c|c|c|c|c|}
\hline \multirow[b]{2}{*}{ Week } & \multicolumn{3}{|c|}{$\mathrm{C}_{8 \mathrm{mT}}$} & \multicolumn{3}{|c|}{$\mathrm{CMF}_{8 \mathrm{mT}}$} \\
\hline & $\begin{array}{c}\text { Food } \\
\text { Consumed } \\
(\mathrm{g})\end{array}$ & $\begin{array}{c}\text { Water } \\
\text { Consumed } \\
(\mathrm{ml})\end{array}$ & $\begin{array}{c}\text { Rectal } \\
\text { Temperature }\left({ }^{\circ} \mathbf{C}\right. \\
)\end{array}$ & $\begin{array}{c}\text { Food Consumed } \\
(\mathrm{g})\end{array}$ & $\begin{array}{c}\text { Water } \\
\text { Consumed } \\
(\mathrm{ml})\end{array}$ & $\begin{array}{c}\text { Rectal } \\
\text { Temperature } \\
\left({ }^{\circ} \mathbf{C}\right)\end{array}$ \\
\hline 1 & $29.7 \pm 5.7$ & $27.8 \pm 4.3$ & $37.1 \pm 0.3$ & $33.8 \pm 7.5$ & $30.4 \pm 5.5$ & $35.6 \pm 5.4$ \\
\hline 2 & $31.3 \pm 6.4$ & $29.6 \pm 6.2$ & $36.9 \pm 0.4$ & $34.7 \pm 6.6$ & $31.4 \pm 6.8$ & $33.5 \pm 5.3$ \\
\hline 3 & $32.2 \pm 6.2$ & $30.3 \pm 5.8$ & $36.9 \pm 0.3$ & $35.6 \pm 5.4$ & $33.5 \pm 5.3$ & $36.9 \pm 0.3$ \\
\hline
\end{tabular}

Impedance measurements have been carried out to determine the relative magnitudes of the time constants (relaxation times) associated to these processes. As expected, relaxation dielectric and specific adsorption time constants are somewhat smaller $(1-100 \mu \mathrm{sec})$ than those involving membrane transport (1-100 msec). Of importance also is the observation that the steady state (DC) current path-way (due to transport) exhibits a specific resistivity several orders of magnitude above that of the extracellular fluid (Pilla et al., 1989). These alterations are frequency sensitive, since the different dynamic behaviours of the channels, and the ion-concentration variations can modify the channel protein environment, changing their permeabilities. As a consequence, the process could be auto-catalytic. Some authors have addressed the specific possibility that the cell membrane lipids are the target of the electromagnetic field interaction at high frequencies. In general, a cell membrane phospholipid is composed of two parts: one head and two tails with similar chemical and physical composition. It has been shown (Seelig et al., 1987) that in some phospholipids, the polar heads align themselves nearly parallel (within $30^{\circ}$ ) to the membrane surface and that the heads' group orientation is identical in the artificial bilayers and in the biological membranes. Different conformations of a phospholipidic bilayer are possible. The transition between one conformation to the other is affected by the concentration of bound water at lipid-water interface, and therefore it can be bound water concentration (hidratation). The presence of the charges or dipolar molecules external to the membrane but in the proximity of the heads can modify the bistable nature of the phospholipidic bilayer (Cevc et al. 1987, Shepherd et al., 1978, Seelig et al., 1987) In this study, the weights of rats exposed to magnetic fields in experimental groups were increased to initial weight. Although the amount of the consumed food and water did not change, increased weight could be due to the changes of the metabolism or hidratation. Recent investigations revealing an increase in insulin release in diabetic rats, increase in glycogen, and decrease in glucose levels in rats exposed to magnetic fields, have provided the stimulus for the current studies. In individuals with normal metabolism the free oxygen radicals that are released to a limited extent are removed by the antioxidative defense systems which provide for the homeostasis of the organism. Free oxygen radicals and lipid peroxides are known to be responsible for the pathogenesis of most diseases including atherosclerosis, infectious diseases, diabetes and cancer (Coudray et al., 1999, Yogi 1984). The living systems generate free radicals as the result of biochemical reactions (e.g. oxidative metabolic processes). The static magnetic fields (on the order of $1 \mathrm{mT}$ ) have been proved to affect the free radical chemical reactions in- vitro (Popp, 1985). This suggests the possibility that modulated magnetic field effects on living systems may involve changes in free radicals. They can be formed by a simple bond-breaking process, in which each of the two electrons of opposite spins forming the bond ends up on a separate radical. The spin is conserved in the reaction so that the electrons in the resulting pair of radicals have opposite spins, at the instant of radical formation. The corresponding radicals constitute a singlet radical pair, whose reaction rate is the influenced by even low magnetic fields (Steiner et al., 1989, 
Popp 1989). In the reaction of pyrene with dimethyaniline, for example, Hamilton et al. (1988) reported a critical static magnetic flux density of $1 \mathrm{mT}$. Under reactions proceed through triplet state, where the electron spins are parallel, and its reaction with another molecule yields a pair of free radicals also in the triplet configuration. Since the bond formation needs a singlet pair, the radicals, which are initially prevented from reacting by having the wrong relative spins, diffuse apart so that the spins may became favourably oriented and the back reaction may occur if they re-encounter. The main effect of magnetic field is the removal of the degeneracy of the energy levels of the triplet radical pair. The change in rate of the above processses under magnetic exposure may be very significant biologically. Furthermore, any molecular region of high local viscosity does not allow the radical to diffuse too far away, so that it may be biologically very active. The difference in energy levels of triplet state electrons is a function of the increasing of magnetic field strength the combined static and modulated magnetic fields could modify the free radical reactions in situations where the intrinsic magnetic flux density was in the range of the critical level. If themodulated magnetic field intensity is equal to the difference between the intrinsic and critical level, and if the period of the field is sufficiently long to permit a transition, the alternating field could act on the biochemical processes. An interesting property of this mechanism is that a relatively small energy exchange between an external magnetic field and a free-radical controlled reaction could induce the physiologically significant changes, since the most of the energy could be given by the biochemical activation energy. The role of the free radicals in the development of complications in diabetes is significantly high. The increase in the production of the free radicals is due to glucose autooxidation, leukocyte activation, and the transition metals (Wolf, 1993). Especially, in the diabetic patients with micro- and macro-vascular complications, the free radicals have been demonstrated to increase the tissue injury whilst suppressing the levels of the various antioxidants (Wolf et al., 1975). The free radicals and peroxides, despite their apparent similarities with diabetogenic agents are believed to play an important role in the relationship between nitric oxide formation and guanilate cyclase activity, peroxidase regulation, and prostaglandin synthesis (Wolf et al., 1975,1993,
Oroza et al., 1987). Bellossi et. al., have demonstrated that the blood cholesterol, glucose and triglyceride levels of diabetic rats were lowered by acute exposure to the magnetic field (Bellossi et al., 1996, 1992). In this study, the plasma glucose levels were decreased in the blood parameters of the healthy and diabetic rats that exposed both the magnetic fields. The decrease of the level of the total cholesterol and triglyceride in the plasma-chemistry of the rats showed that the magnetic fields affected the hormonal systems, directly or indirectly and slowed down the metabolism. The increase of liver organ compared to the body that Bellossi and Kost et al (Bellossi et al., 1996,1992, Kost et al., 1987) observed while applying acute magnetic fields applied to healthy and diabetic rats caused to slow down the metabolism that caused the change of the homeostasis of the living-organism and enhanced insulin release to the diabetic rats. The liver plays an important part in the general metabolism, especially diabetic mellitus patients and very probably plays a part in the healing process. (Bellossi et al., 1996, 1992, Behari et al., 1997, Oroza et al., 1987) The magnetic field was suggested to decrease the metabolism of the liver. As a result of slowdown liver metabolism, the production of oxygen-derived free radicals may be decrease on metabolism. Whether alternative modulated magnetic field exposure have a positive or negative effect of both the healthy and diabetic rats can only be confirmed after examination of the stress factors, free radicals and liver metabolism.

\section{ACKNOWLEDGMENT}

This study was supported by grants from Cukurova University Scientific Research Foundation.

\section{REFERENCES}

Behari J. and Mathur R. (1997). Exposure effects of staticmagnetic field on some physiological parameters of developing rats. Indian Journal of Experimental Biology, 35 894-897.

Bellossi A, Pauvreau-Quillien V.,. Rocher C,.Ruelloux M. (1996). Effect of pulsed magnetic fields on cholesterol and tryglyceride levels in rats study of field intensity and length of exposure. Z.Naturforsch, 51 c 603-606. 
Bellossi A, Pouvreau-Quilien V, Rocher C.,.Reulloux M. (1998). Effect of pulsed magnetic fields on triglyceride and cholesterol levels in plasma of rats. Panminerva Med, 40 276-9.

Bellossi A. (1992). Effects of a $12 \mathrm{~Hz}$ and $460 \mathrm{~Hz}$. pulsed magnetic field on the weight of AKR mice. Biotherapy 4 277-283.

Cevc G,.Marsh D. (1987). "Phospholipid bilayers: physical principles and models,", John Wiley and Sons, New York, Chatham J.C,. Forder JR. A. (1993). ${ }^{13} \mathrm{C}-\mathrm{NMR}$ study glucose oxidation in the intact functioning rat heart following diabetes-induced cardiomyopathy. J Mol Cell Cardiol, 25 1203-1213.

Coudray C.F., Rock E., Coudray C.,. Grzelkowska K, Braesco-Azais V. Dardevet D. (1999).

Mazur A.. Lipid peroxidation and antioxidant status in experimental diabetes. Clinica Chimica Acta 28431 43.

Daşdağ S., Balcı K, Çelik M.S., Batun S., Kaplan A, Bolaman Z., Tekeş S. (1993). Rf ve mikrodalgalara mesleki olarak maruz kalanlardaki nörolojikbiyokimyasal bulgular ve CD4/CD8 oran1. V. Ulusal Biyofizik Kongresi İzmir.

Franceschetti G, Gandhi Om. P, Grandolfo M.(1989). Electromagnetic Biointeraction. Plenum Press, NewYork, London.

Gordon R.T and.Gordon D. (1981). Selective resolution of plaques and treatment of atherosclerosis by biophysical alteration of "cellular" and "intracellular" properties.Medical Hypotheses, 7 217-229.

Hameroff S.R (1990). Coherence in the cytoskeleton: Implications for biological information processing. In: Biological Coherence and Response to External Stimuli (H.Frohlich, ed.). Springer-Verlag, Berlin, p.242.

Hamilton C.A.,. Hewitt J.P,. McLauchlan K.A and. Steiner U.E. (1988). "High Resolution Studies of the Effects of Magnetic Fields on Chemical Reactions," Molecular Physics 65 423-438.

İteğin M.,. Günay İ,. Loğoğlu G, İsbir T. (1995). Effects of static magnetic field on specific -adenosine-5'triphosphatase activities and bioelectrical and biomechanical properties in the rat diaphragm muscle. Bioelectromagnetics, 16 147-151.

Jauchem J.R.,. Meritt J.H. (1991) The epidemiology of exposure to electromagnetic fiels: An overview of the recent literature. J.Clin.Epidemiol. Vol.44-9, pp:895906

Kost J, Wolfrum J.,.Langer R (1987), Magnetically enhanced insulin release in diabetic rats. $J$ Biomed Materials Res, 21 1367-1373.

Mann S.,. Webb J.,. Williams R.J.P. (1989). Biomineralization: Chemical and Biochemical Perspectives, VCH Verlagsgesellshaft Weinheim, Germany.
McLaughin S. (1989). The role of electro-osmosis in the electric-field-induced movement of charged macromolecules on the surfaces of cells. Biopys. J., 34 85-93.

McLauchlan K.A. and. Steiner U.E. (1991). The spincorrelated radical pair has a reaction intermediate, Molec Phys, 24173

McLauchlan K.A. (1992). Are environmental magnetic fields dangerous?, Physics World, Meldrum F.C.,. Heywood B.R,.Mann S. (1992). Magnetoferritin: In Vitro Synthesis of a Novel Magnetic Protein, Science, 257522.

Ocal I. and Gunay I. (2004). The Effects of Chronic AC Magnetic Field on Contraction and Relaxation of Isolated Thoracic Aorta Rings of Healthy and Diabetic Rats Vol.47, n. 5 pp. 733-738.

Oroza M.A, Calcice L,. Sanchez-Fkanco F,.Rivas L. (1987). Hormonal, hematological and serum chemistry effects of weak pulsed electromagnetic fields on rats. Journal of Bioelectricity, 6(2)), 139151.

Pilla, A.A., and Margules, G.S. (1977). Dynamic interfacial electrochemical phenomena of living cells: application to the toad urinary bladder membrane systems, Electrochem.Soc., 1241697.

Popp F.A.(1985).Nuovi Orizzonti in Medicina. La teoria dei Biofotoni. IPSA Editore, Palerma

Popp F.A,. Warnke U, Konig HL,. Peschla W. (Editors) (1989). Electromagnetic Bio-information. Uran and Schwarzenberg, Munchen.

Seelig J.,. Macdonald P.M, and Scherer P.G. (1987). Phospholipid head groups as sensors of electric charge in membranes, Biochem., 247535.

Shepherd J. C.W, and Büldt G. (1978). Dielectric measurements on reorientation rates in lipid head groups Biochim. Biophys. Acta, 51483.

Steiner U.E, , and. Ulrich T. (1989) Magnetic Effects in chemical kinetics, and related phenomena, Chem; Rev, 5189.

Suess M.J, Benwell D.A-Morison (1989). Nonionising Radiation Protection $\mathrm{WHO}$.

Wolf S.P,. Song J,. Hunt JV. (1975). Protein glycetion and oxidation stress in Diabetes mellitus and ageing Contemporary Issues in Endocrinology and metabolism NewYork Churchill Livingstone Inc. Vol 223.

Wolf S.P. (1993) Diabetes mellitus and free radicals. $\mathrm{Br}$ Med Bull, 49(3) 642-52.

Yogi K. (1984). Increased lipid peroxides initiate atherogesis. Bio Essays, 58-60.

Received: June 09, 2005; Revised: August 10, 2006; Accepted: April 02, 2008. 